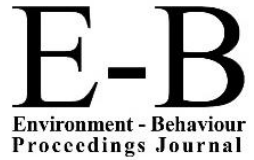

Proceedings Journal

\section{ASLI 2018 \\ AicQoL2018PerhentianIsland \\ http://www.amerabra.org; $h$ ttps://fspu.uitm.edu.my/cebs $6^{\text {th }}$ AMER International Conference on Quality of Life \\ Pulau Perhentian Resort, Malaysia, 03-04 March 2018 \\ "Quality of Life in the Built \& Natural Environment 6"}

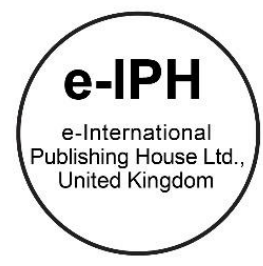

\title{
Youth in Vertical Housing Neighbourhood Space: A focus group discussion
}

\author{
Kamarul Ariff Omar ${ }^{1 *}$, Dasimah Omar ${ }^{1}$, Saberi Othman², Zaharah Mohd Yusoff ${ }^{1}$ \\ ${ }^{1}$ Faculty of Architecture, Planning and Surveying, \\ University of Teknologi MARA (UiTM), 40450 Shah Alam, Selangor, Malaysia \\ 2Faculty of Science and Mathematics, \\ Universiti Pendidikan Sultan Idris (UPSI), 35900 Tanjong Malim, Perak Malaysia ${ }^{2}$
}

kamarulariffomar@gmail.com; dasimaho@yahoo.com; saberi@fsmt.upsi.edu.my; zmy_1208@yahoo.com $+60173663203$

\begin{abstract}
Focus group discussion series was set up at the vertical housing of Kerinchi People Project Housing, Lembah Pantai with two different group in separate venue and time. The analysis was done by using Atlas.ti after transcribing and coding the audio-taped of discussion, searching for networking on youth participation. The finding shows youth demandingly indoor space compared to outdoor space due to open space inadequacy and absence of space quality yet lost the sense of belonging. Furthermore, the residents' committee neglected youth participation in decision-making process or meeting with the committee, has resulted from youth not to actively participate in the community.
\end{abstract}

Keywords: youth; vertical housing; neighbourhood space; focus group discussion

eISSN: 2398-4287C 2018. The Authors. Published for AMER ABRA cE-Bs by e-International Publishing House, Ltd., UK. This is an open access article under the CC BYNC-ND license (http://creativecommons.org/licenses/by-nc-nd/4.0/). Peer-review under responsibility of AMER (Association of Malaysian Environment-Behaviour Researchers), ABRA (Association of Behavioural Researchers on Asians) and cE-Bs (Centre for Environment-Behaviour Studies), Faculty of Architecture, Planning \& Surveying, Universiti Teknologi MARA, Malaysia.

DOI: https://doi.org/10.21834/e-bpj.v3i7.1271

\subsection{Introduction}

Youth living in vertical housing scheme face the difficulties in participating neighbourhood space and blend with the community as some of the residents misuse the space and marginalised youth appearance. Nowadays trend led this adolescent to perform indoor activities and causing the value of natural social interaction to be rapidly decreased. Indoor activities are much easier to accomplish since the vertical housing scheme provides more indoor space compared to outdoor space. As mentioned by Browning \& Soller (2014), youth are exposed to be marginalised for participating in the neighbourhood without an appropriate environment setting or planning. The marginalisation also happened as adolescence were unaware and not thoroughly blend into space and community. Schmid et al. (2011) had developed a method of measuring youth development using future expectations and intentional self-regulation relationship; Crean (2012) investigated youth involvement related to adult support and individual decision-making skills; Yeshpanove D. et al., (2014) indicated youth activity related to social and cultural measurement; and the latest research by Forrest-Bank et al., (2015) on positive youth development was throughout the perception of risk and resilience of public housing neighbourhoods. Due to this scenario, this paper aimed to outline youth marginalisation in space and community of vertical housing neighbourhood.

\subsection{Youth in Vertical Housing Neighbourhood Space}

Youth is indicated as a person between the age where he/she may leave compulsory education, and the age at which he/she finds his/her first employment. As studied by Raja Suzana Raja Kasim et al. (2014), in Malaysia there were 13.3 million youth population ages

eISSN: 2398-4287@ 2018. The Authors. Published for AMER ABRA cE-Bs by e-International Publishing House, Ltd., UK. This is an open access article under the CC BYNC-ND license (http://creativecommons.org/licenses/by-nc-nd/4.0/). Peer-review under responsibility of AMER (Association of Malaysian Environment-Behaviour Researchers), ABRA (Association of Behavioural Researchers on Asians) and cE-Bs (Centre for Environment-Behaviour Studies), Faculty of Architecture, Planning \& Surveying, Universiti Teknologi MARA, Malaysia.

DOI: https://doi.org/10.21834/e-bpj.v3i7.1271 
between 15 to 40 represented $46 \%$ of the total Malaysian population. Youth should dynamically take part in the community programme in making the society more liveable and efficient to all age group inside the community social hierarchy. Moreover, applying broad and continuous action plan and contribution for youth does not necessarily mean better outcome, but this action may recognising and integrating the different perception of the adult and adolescent $(\mathrm{Li}, \mathrm{H}$. et al., 2015). There is a profusion of knowledge for influence factors on participation in the community. As indicated by Nyambe, A. et al. (2016), the Socio-Ecological model (SEM) influences or determinants of involvement can relate to intrapersonal, interpersonal, organisational, environmental, and policy factors. One key impact on participation mentioned by Benner, A. D., Boyle, A. E., \& Sadler, S. (2016) is Socio-Economic Status (SES). However, the shortage of space in neighbourhood public housing assumed to limit individual participation and interaction within their living environment (Chitrakar, R. M., Baker, D. C., \& Guaralda, M., 2016). The availability of space has influenced user behaviour, physical activity and social interaction. As stated by Marouf, N. et al. (2015), "youth have fewer chances for outdoor activities due to increasing of variety technology upon communication, loss of outdoor space due to infrastructure demand and indoor activities trend of interest due to current working hour scenario (Vilhelmson, B., Thulin, E., \& Elldér, E., 2017). This is evident with the rapid economic development and industrial construction in many emerging industrialized countries, particularly in Asia big cities. As a result, there are limited outdoor activity venues in urban areas especially for strata housing schemes (Sherry, C., 2017), which minimizes their outdoor activity and consequently affects their contacts with the community.

Lands are inadequate resources, especially in the city (Yusup, M. et al., 2016). Pressures from housing sector mean more lands are needed to build the house. The number of the vertical building has increased all over the world. The rapid process of urbanisation and industrialisation has brought about the densely populated cities as geographically and socially aggregate areas full of economic tendency. There are few factors contributed to the vertical living; urbanisation, increase in land value, lifestyle and scarcity of land. In Malaysia, the concept of vertical living has been introduced as early as seventieth. The vertical living concept has become popular in the major city which are Klang Valley, George Town and Johor Bahru. The acts including The National Land Code, Strata Title Act 1965 and Strata Management Act 2013 have been constituted for strata management in Malaysia. However, there appear to be several weaknesses in managing strata properties especially in dealing with the residents' satisfaction. Although, many acts applied in strata management demanding of space in every housing scheme to trigger the shortage of space by abandoning the outdoor activities (Hilber, C. A., 2015).

According to Gidlow et al., (2012), neighbourhood space is a place for a community to accomplish good quality of life driven by balance social interaction and physical activity along with positive acceptance and manners. Vertical housing in this study is a neighbourhood unit as residence access the neighbourhood space without exorcising age division, gender inequality, race discrimination and political differences. In designing neighbourhood space is diverge to encompass the human needs, environmental character, aesthetic values, sense of belonging and liveability for delivering the better quality of life. Neighbourhood space like public open space create enjoyable scenery, play a role in supporting social interaction and emphasise physical activities among the residents (Cauwenberg et al., 2015). According to Zieff et al., (2016) a quality neighbourhood space is likely to smooth chances for youth to physically active and socially engaged.

\subsection{Focus Group Discussion}

FGD is methods of data collection outline the number of participants in each group to improve interactivity, and the research question itself lead researchers to decide the number of focus groups is needed to be run. The use of 2-5 focus groups is well-documented (Twohig \& Putnam 2002).It is naturally controlled by one moderator but can sometimes be assisted by a transcriber or other team members. For valuation purposes, a focus group will regularly involve 8-12 members and can last anywhere from 1-2 hours. Fortunately, focus group allows researchers to observe and pay attention to visual aspects such as respondents' body language and facial lingos as they are given topics to discuss. Researchers have defined the code name for each respondent from both FGD to make the quotation easy to analyse and code based on themes and questions. Therefore, looking at the limitation of this study, two focus groups had been conducted to represent youth and stakeholder. Both discussions were held in separate venues and time in accordance with researchers' and participants' schedule.

\subsection{Participation Selection}

The selection of participation should have a clear justification and satisfy a specific purpose related to the research question, which is why qualitative methods are defined as 'purposive' (Collingridge \& Gantt 2008). The first FGD was attended by twelve youths who lived in Kerinchi People Project Housing, Lembah Pantai. These youth participants were chosen to represent each of six blocks in this neighbourhood. They were interviewed to express the opinion and shared the feeling upon the neighbourhood space, public facility and social interaction within their living environment. They were selected randomly on behalf of female and male gender, age between 15 to 25 years old and represent the dominant ethnic lived in this neighbourhood. The second FGD was representing the stakeholders which consist of nine participants represented by three Residents' Committee members, a Town Planner from Kuala Lumpur City Hall (DBKL), a Town Planner from Department of Town and Country Planning Malaysia and four members of the Malaysian Youth Council (MYC).

Table 3.1: Profile of Participants in each Focus Group Discussion

\begin{tabular}{|c|c|c|c|c|c|}
\hline Youth FGD & & & Stakeholders FGD & & \\
\hline Background & Participant & Coding & Background & Participant & Coding \\
\hline
\end{tabular}




\begin{tabular}{|c|c|c|c|c|c|}
\hline $\begin{array}{l}\text { Un-employed } \\
\text { (Ya) }\end{array}$ & 1 & Y1 & $\begin{array}{l}\text { Residents' Committee } \\
\text { (Sa) }\end{array}$ & 3 & $\begin{array}{l}\text { S1 } \\
\text { S2 } \\
\text { S3 }\end{array}$ \\
\hline $\begin{array}{l}\text { Employee } \\
(\mathrm{Yb})\end{array}$ & 3 & $\begin{array}{l}Y 2 \\
Y 3 \\
Y 4\end{array}$ & $\begin{array}{l}\text { Youth Association } \\
\text { Committee } \\
\text { (Sb) }\end{array}$ & 4 & $\begin{array}{l}\text { S4 } \\
\text { S5 } \\
\text { S6 } \\
\text { S7 }\end{array}$ \\
\hline $\begin{array}{l}\text { Secondary School } \\
\text { Student } \\
(\mathrm{Yc})\end{array}$ & 4 & $\begin{array}{l}\text { Y5 } \\
\text { Y6 } \\
\text { Y7 } \\
\text { Y8 }\end{array}$ & $\begin{array}{l}\text { Government Agency } \\
\text { (Sc) }\end{array}$ & 2 & $\begin{array}{l}\text { S8 } \\
\text { S9 }\end{array}$ \\
\hline $\begin{array}{l}\text { University Student } \\
(Y d)\end{array}$ & 4 & $\begin{array}{l}\text { Y9 } \\
\text { Y10 } \\
\text { Y11 } \\
\text { Y12 }\end{array}$ & & & \\
\hline
\end{tabular}

\subsection{Venue and Time}

The first FGD was held at the community hall of "Kerinchi People Project Housing" on the afternoon of 3-5pm. The time was appropriate for the youth as they were at schools in the morning. The second FGD group was held at 10am-12pm at Armada Hotel, Petaling Jaya. The venue selected is located close to the study area and within accessibility of other stakeholders'. These FGDs were held at two different venues between September 2014 and November 2014.

\subsection{Conducting the Discussion}

The lead researcher had appointed a speaker and moderator to deliver the questions properly and easy to understand. In every session, all respondents introduced themselves as they eventually know each other. Information obtained from all respondents is used to verify and confirm the assumption highlighted from literature review and information on the scenario of youth in the vertical housing neighbourhood space in Malaysia. The questions asked of the stakeholders and youths were all open-ended question, obtaining final answers comprehensively and closed to the researcher objective. The entire process of semi-structured interview was improvised and conversational, while key points and answers are recorded on a form designed to evaluate and sorting the answers. This has given respondents chances of sharing reliable information and ease researchers to extract the answers. Researchers had taken all respondents' point of views, which were essential and related to the objective and questions asked.

\subsection{Data Analysis}

Transcribing method was used to extract data from FGD conversation and interview to analyse the result findings. This process will retrieve each word from audio recorded-tape in both FGD sessions. The researcher has to transcribe each conversation into a formal sentence according to question theme and coding the keyword quoted by respondents. It is not an easy way to transcribe each word derive by respondents as some of them used them yet, the researcher only focuses on accurate statement and alert on each critical word related to the question. By using earphone and audiotaped material, researcher managed to transcribe both FGD in two months including proofreading by a respective panel and reported the transcript for coding stage. It should be aware that transcript will not be able to represent the whole interview setting. As it is, one focus aspect must be highlighted, and a complete transcript is necessary if the following analysis does not merely focus on the significant content of a conversation.

\subsection{Result of Findings}

\subsection{Youth Focus Group Discussion}

Table 4.1 reveals the relationship between respondents and coding phrase and theme is slightly average and not reliable. In neighbourhood space, five (5) coding phrases had been identified by the researcher frequently response by respondents. Four (4) respondents preferred indoor space compared to three (3) respondents who were for outdoor space. There is a similarity between the youth group who choose to be passively stayed in the house or at the cyber café as they were struggling to manage their living condition. As for the youth in the school age, they rather are actively in the outdoor space like the soccer field, multi-purpose court or playground having leisure and recreational activities. The problem was raised by three (3) respondents (Y4, Y6, Y10) as two of them (Y4, Y10) denied participating in outdoor space due to limited space and time constraint. However respondent (Y6) preferred outdoor space because of space in the house was packed with other family members. Precisely, (Y10) has responded by explaining the implication of not choosing outdoor space because she is not in the close relationship with the community as she is only a tenant and busy with her university life.

Referring to a public facility, three (3) respondents ( $Y 1, \mathrm{Y}$, and $\mathrm{Y} 8$ ) agreed that the facility is available for the youth but five (5) other respondents (Y5, Y6, Y7, Y8, Y12) responded the facility was insufficient. However, from five (5) respondents, three (3) of them (Y5, Y6, Y7) stated that the problem about inadequate public facility due to the limited number of unit and lack of choice in public facility. From the three (3), (Y5 and Y7) highlighted the implication has led to the problem of not participating in the neighbourhood space. Although $(Y 6)$ responded to the insufficiency of the facility, he prefers to be an outdoor space. Hence, ( $Y 6)$ does not require the public facility to participate in the neighbourhood space actively. As for the suggestion, (Y6, Y7 and Y12) manage to overcome the problem by 
looking for another option of activities or space outside the neighbourhood. However, only one respondent (Y8) prefers existing facility and choose to be in this neighbourhood space.

Regarding with social interaction and participation, only (Y1) has involved in the community under the neighbourhood women society as she is unemployed and a full-time housewife allows her some time to interact and participate with others. While five (5) respondents (Y3, Y5, Y6, Y7 and Y8) stated be marginalised. The residents' committee has marginalised these youth from participating or involving to voice out ideas or views. As ( $Y 5$ and $\mathrm{Y} 7$ ) revealed the bureaucracy set by the committee members had driven the marginalisation of adolescent to be part of the organisation yet $(Y 8)$ responded there is no such association or bureau link to the committee for youth to participate.

Table 4.1: Youth Respondents' Code based on Theme of discussion

\begin{tabular}{lll}
\hline Theme & Code & Respondents \\
\hline Neighbourhood Space & Indoor space & Y1, Y3, Y4, Y10 \\
& Outdoor space & Y6, Y8 \\
& Problem & Y4, Y6, Y10 \\
& Implication & Y1, Y3, Y10 \\
& Suggestion & Y4 \\
\hline Public Facility & Availability & Y1, Y3, Y8 \\
& Sufficiency & Y5, Y6, Y7, Y8, Y12 \\
& Problem & Y5, Y6, Y7 \\
& Implication & Y5, Y7, \\
& Suggestion & Y6, Y7, Y8, Y12 \\
\hline Social Interaction and Participation & Involvement & Y1 $1, Y 6$, Y7, Y8 \\
& Marginalise & Y3, Y5, Y6 \\
& Committee & Y3, Y5, Y7 \\
& Community & Y1, Y6, Y8 \\
& Problem & Y3, Y5, Y6, Y7, Y8 \\
\hline
\end{tabular}

\subsection{Stakeholders' Focus Group Discussion}

Table 4.2 depicts the relationship between respondents, and the coding phrase is moderate but not influential among them. In neighbourhood space, only six (6) respondents responded to the questions asked by the moderator. Two (2) respondents (S8 and S9) indicated the government prefers more vertical housing focuses on the number of the unit compared to open space provision. Four (4) respondents (S1, S2, S3 and S6) revealed that there is a shortage of outdoor space in this vertical housing scheme. Respondents (S1, S2) justified the problem of outdoor space and its implication to the youth as they cannot be part of the community due to limited outdoor space.

In relation to public facility, seven (7) respondents (S1, S2, S3, S5, S7, S8, and S9) agreed there is no facility available there suitable for youth while five (5) of them (S1, S2, S3, S8 and S9) notified the existing facility was not sufficient to serve the youth and the whole population in this neighbourhood. Furthermore, the problem of facility insufficiency was highlighted by three (3) respondents from the committee (S1, S2 and S3) as they are familiar with the surrounding environment and had faced the scenario from the time they moved into this neighbourhood. The respondents from government sector (S8, S9) outlined the insufficiency was due to the implementation of the facility based on the guideline to serve the overall population. Meanwhile, the NGOs, not able to visualise the scenario as the committee members did, yet they responded and voiced out the right of youth based on complaint and report.

In social interaction and participation, three (3) respondents (S1, S6, S8) responded youth from this vertical housing schemes did not involve either to committee either community nor to decision making at the higher level. Another three (3) respondents (S2, S4, and S7) admitted, youth were marginalised mainly to participate in the committee. It was different between not involve and being marginalised, as respondents $(\mathrm{S} 6, \mathrm{~S} 8)$ responded that youth were not involved with the community because they were struggling to survive with the urban lifestyle.

Table 4.2: Stakeholder Respondents' Code based on Theme of discussion.

\begin{tabular}{lll}
\hline Theme & Code & Respondents \\
& & \\
\hline Neighbourhood Space & Indoor space & $\mathrm{S} 8, \mathrm{~S} 9$ \\
& Outdoor space & $\mathrm{S} 1, \mathrm{~S} 2, \mathrm{~S} 3, \mathrm{~S} 6$ \\
& Problem & $\mathrm{S} 1, \mathrm{~S} 2, \mathrm{~S} 3, \mathrm{~S} 6, \mathrm{~S} 8, \mathrm{~S} 9$ \\
& Implication & $\mathrm{S} 1, \mathrm{~S} 2$ \\
& Suggestion & - \\
\hline Public Facility & Availability & $\mathrm{S} 1, \mathrm{~S} 2, \mathrm{~S} 3, \mathrm{~S} 5, \mathrm{~S} 7, \mathrm{~S} 8, \mathrm{~S} 9$ \\
& Sufficiency & $\mathrm{S} 1, \mathrm{~S} 2, \mathrm{~S} 3, \mathrm{~S} 8, \mathrm{~S} 9$ \\
& Problem & $\mathrm{S} 1, \mathrm{~S} 2, \mathrm{~S} 3, \mathrm{~S} 8, \mathrm{~S} 9$ \\
& Implication & $\mathrm{S} 8, \mathrm{~S} 9$ \\
& Suggestion & $\mathrm{S} 1, \mathrm{~S} 5, \mathrm{~S} 7, \mathrm{~S} 8, \mathrm{~S} 9$ \\
\hline Social Interaction and Participation & Involvement & $\mathrm{S} 1, \mathrm{~S} 6, \mathrm{~S} 8$ \\
& Marginalise & $\mathrm{S} 2, \mathrm{~S} 4, \mathrm{~S} 7$ \\
& Committee & $\mathrm{S} 1, \mathrm{~S} 2, \mathrm{~S} 4, \mathrm{~S} 7$ \\
& Community & $\mathrm{S6}, \mathrm{S} 8$ \\
& Problem & $\mathrm{S} 1, \mathrm{~S} 2, \mathrm{~S} 7, \mathrm{~S} 8$ \\
\hline
\end{tabular}




\subsection{Thematic Analysis}

The researcher had identified three (3) stages of responses; problem identification, examine the implication and provide the suggestion. The networking of every code was connected to every group of respondents in the FGDs session.

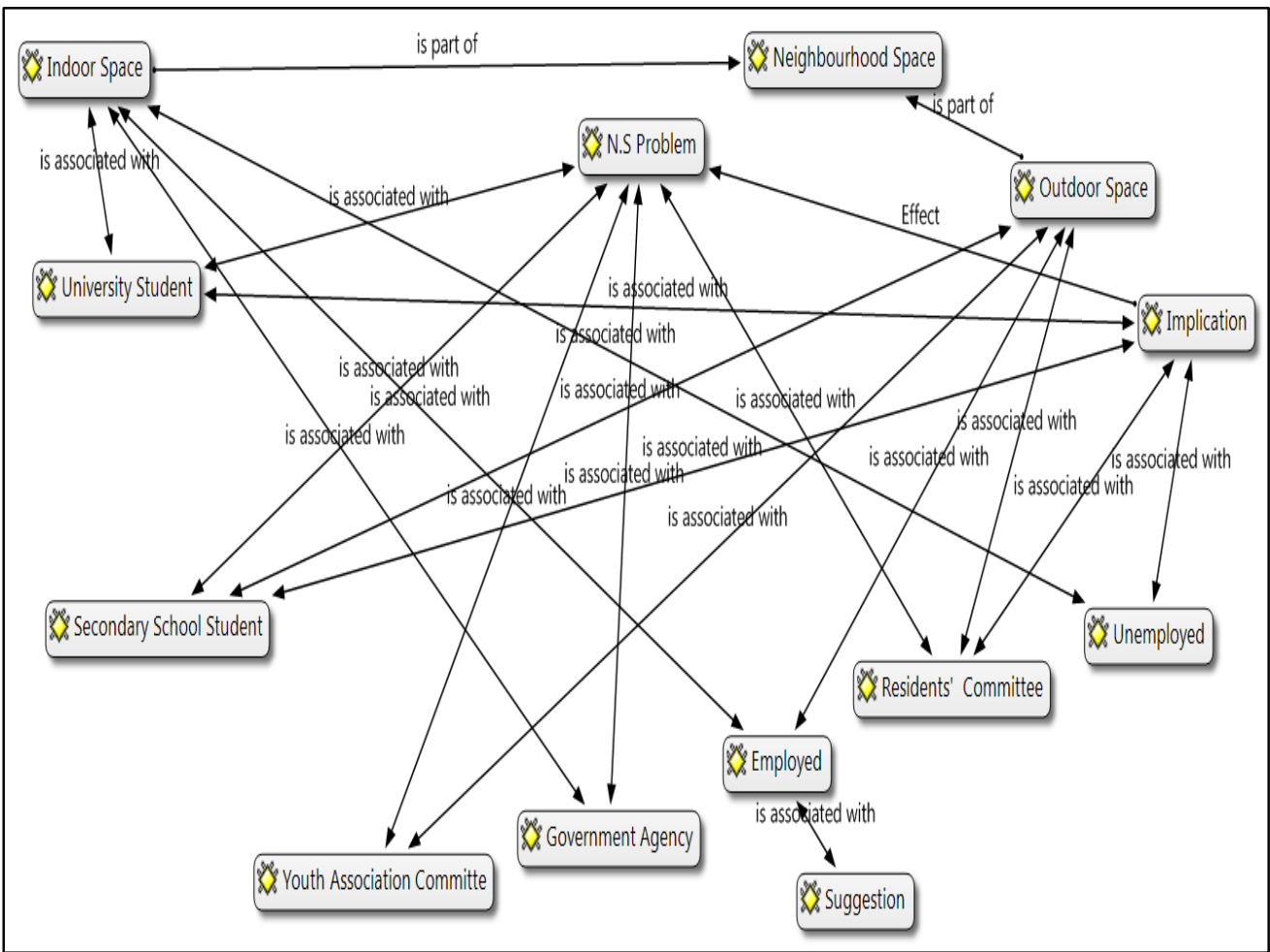

Figure 4.1: Thematic analysis of Neighbourhood Space.

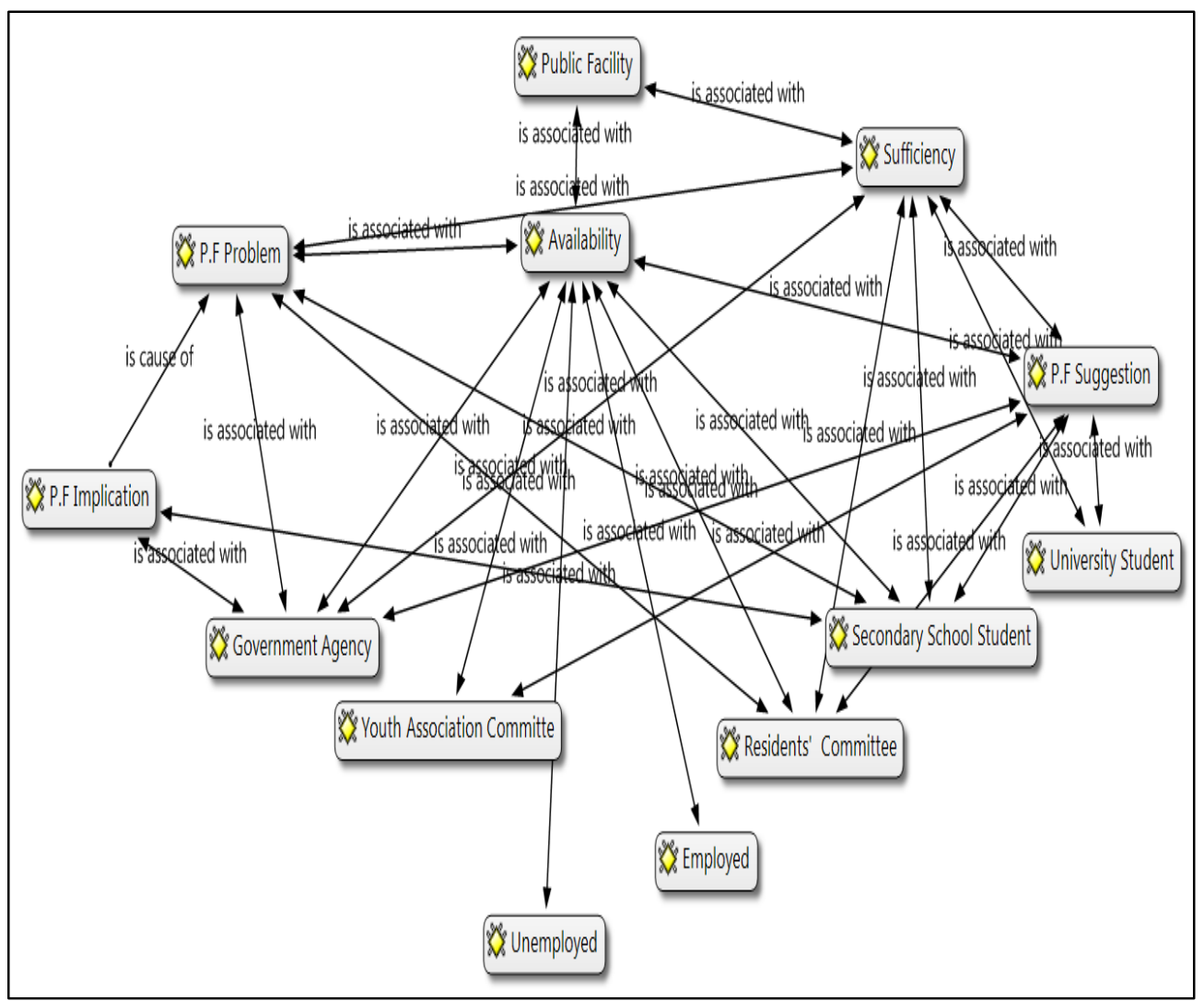

Figure 4.2: Thematic analysis of Public Facility. 
Figure 4.1 shows the networking of every respondent group with the group of responses for the discussion. As for youth, the secondary school youth and university student had responded by justifying the problem and implication, but they were not able to provide a suggestion. Nevertheless, the unemployed group of youth able to examine the implication based on the problem outlined by another group. The working group can provide suggestion based on implication and problem raised by the other group. In the stakeholders' group discussion, all group members able to respond on identifying the problem but the residents' committee member managed to justify the implication of the problem. The NGOs and government sector should be capable of providing a solution upon the problem, but they did not respond.

Figure 4.2 shows the networking of respondents' responses stage in the public facility subject of discussion. In youths' FGD, the secondary school student has responded in identifying problem, examine the implication and provide the suggestion but the university student only outlined the suggestion to overcome the facility insufficiency. Nevertheless, the unemployed and employed youth did not respond for identifying the problem or any implication yet they agreed to verify the availability of the facility. For stakeholders, all groups had identified the problem, but only the government agency should examine the implication based on governance perspective with some suggestion. The NGOs and residents' committee had provided some suggestions to the problem, and the idea was to solve the insufficiency of a facility. They were not looking on how to solve the implication about the neighbourhood space.

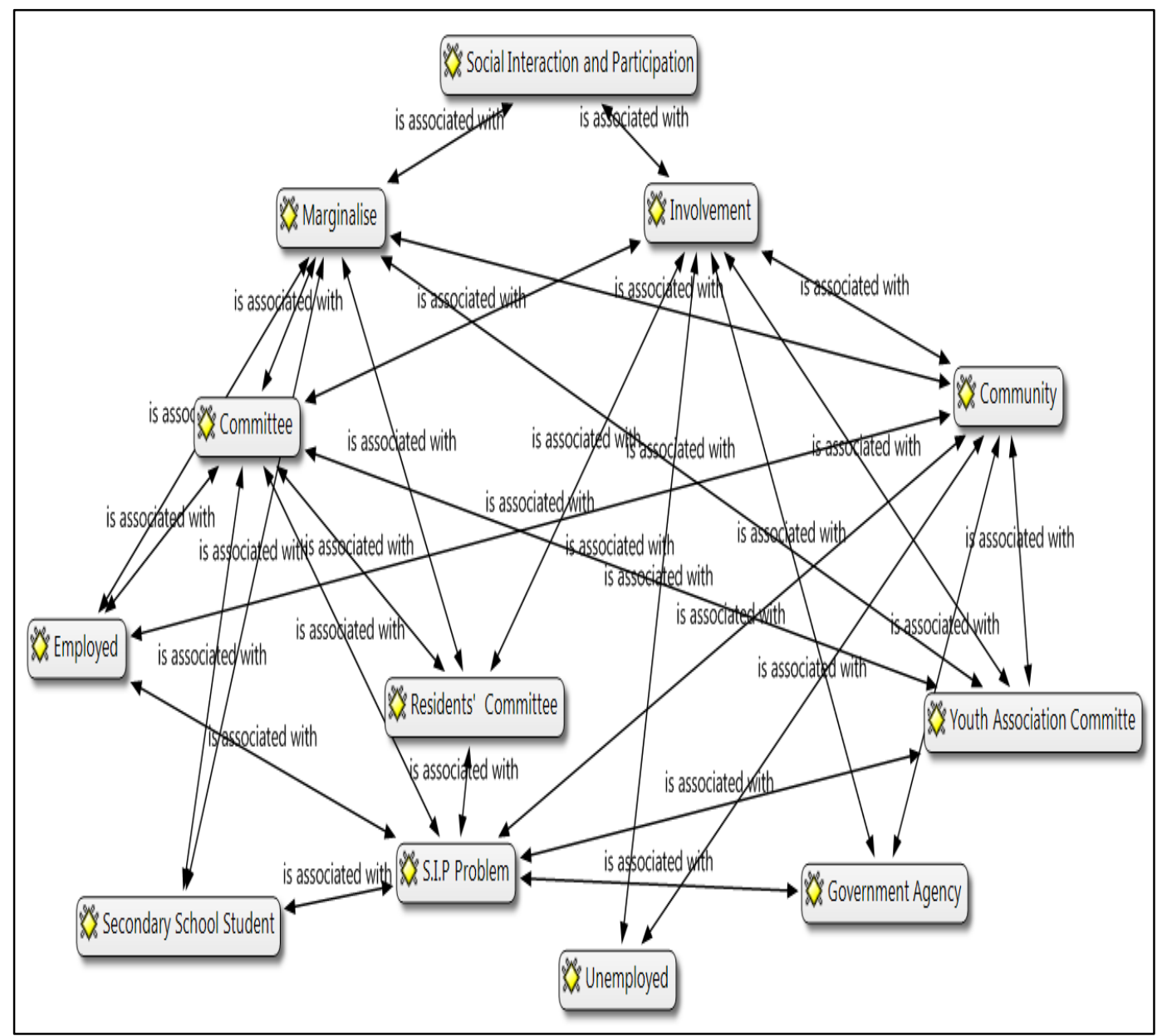

Figure 4.3: Thematic analysis of Social Interaction and Participation.

Figure 4.3 shows the social interaction and participation responses by respondents. The researcher has to illustrate the connection of each respondent during the involvement and marginalization. There is no university student responded to this discussion as they felt no interest to socialise with the community in this neighbourhood. The employed youth and school student stated they had been marginalized within the committee organization or program. At some point, the marginalization occurred in the community interaction as the employed youth was misunderstood by some residents for not being actively participating with them as they were busy working day and night. Meanwhile, the residents' committee members refused to accept youth representative in the organization because most of them did not contribute ideas in the committee meetings. The NGOs argued on the residents' committee perception of youth for not actively giving ideas, because they were not given a chance to sit in any committee meeting. Meanwhile, the government agency's respondent agreed that youth should actively participate in any decision making the process or community meeting to share their desire and opinion as the government will provide better space and facility for the people. 


\subsection{Discussion and Conclusion}

It seems coherent that youth living in the vertical housing neighbourhood have not intensively participated within the space and community. For this reason, the enjoyable form of neighbourhood spaces is associated with the presence of more people, yet they were the victim of inappropriate environment space design for high-density housing scheme as mentioned earlier by Browning \& Soller (2014). The involvement of all individual should not be marginalised by another group of people especially the adolescent just because the adults did not care about these groups' livelihood (Crean, 2012) and the culture does not suit on nowadays youth lifestyle (Yespanove, $\mathrm{D}$ et al., 2014). This group was marginalized as they faced problem in accessing the space and facility because of unavailable and insufficiency (Marouf, N. et al., 2015). The neighbourhood space should be allocated strategically to serve better accessibility and encourage people to get actively socialise because youth lived in this vertical housing preferring more enjoyable inside the house (Sherry, C., 2017) as space and facility were not adequate (Hilber, C.A., 2015) neither available for them.

In social interaction and participation discussion, the attitude of some people inside the community (Forrest-Bank et al., 2015) does not seem to accept youth directly into their organizational of committee body yet the youth itself of not actively getting interact with them. As for the committee member, youth do not have good communication skill while they were put together in the meeting session. Eventually, the NGOs arguably that adolescent should be exposed to be part of any organizational and decision-making process to develop youth confident level and encourage their soft-skill to interact with other people (Li, H. et al., 2015). As a good neighbourhood community, they should not contradict youth appearance and involvement and intent to guide these group to become better generation in the future (Zieff et al., 2016). They must help the youth to be a better person and motivate them to be the pillar for future development towards a better quality of life and healthier living environment.

As the conclusion, youth lived in this vertical housing neighbourhood space did not involve with the community especially employed and university student because they were too busy handling their life and out of expectancy to be part of the community just because they did not have proper interaction to the local people. From the community's perception, this adolescent at the age of 15-18 years old is not appropriate to be involved in the committee discussion due to bureaucracy system and the committee members were not impress by the youth behaviour and their communication skills. Youth were also facing on insufficiency of space and facility in mobilizing them to participate in the community and other people. The uprising issue within this vertical housing scheme is space and facility's insufficiency. The neighbourhood does provide the facility, but the number is inadequate especially for the youth. The government sector needs to emphasize this matter by encouraging youth's voice and involvement in the decision making procedure. The community should support government's implementation policy by considering youth and accepting them as part of their committee members. Youth should be guided and supported by the whole community to develop them as the leaders of the future generation.

\section{Acknowledgement}

This study is made possible by the Long-term Research Grant Scheme (LRGS 2014-0006-106-42), Universiti Pendidikan Sultan Idris Perak associated with Universiti Teknologi MARA Shah Alam, and Universiti Putra Malaysia. Special thanks to the supportive supervisor and kindness co-supervisors in supporting the success of this research.

\section{References.}

Benner, A. D., Boyle, A. E., \& Sadler, S. (2016). Parental involvement and adolescents' educational success: The roles of prior achievement and socioeconomic status. Journal of youth and adolescence, 45(6), 1053-1064.

Browning, C. R., \& Soller, B. (2014). Moving beyond neighborhood: Activity spaces and ecological networks as contexts for youth development. Cityscape (Washington DC), 16(1), 165.

Chitrakar, R. M., Baker, D. C., \& Guaralda, M. (2016). Urban growth and development of contemporary neighbourhood public space in Kathmandu Valley, Nepal. Habitat International, 53, 30-38.

Crean, H. F. (2012). Youth activity involvement, neighborhood adult support, individual decision making skills, and early adolescent delinquent behaviors: Testing a conceptual model. Journal of Applied Developmental Psychology, 33(4), 175-188. doi:10.1016/j.appdev.2012.04.003

Collingridge D.S. \& Gantt E.E. (2008) The quality of qualitative research. American Journal of Medical Quality 23(5), 389-395.

Eusuf, M. A., Mohit, M. a., Eusuf, M. M. R. S., \& Ibrahim, M. (2014). Impact of Outdoor Environment to the Quality of Life. Procedia - Social and Behavioral Sciences, 153, 639-654. doi:10.1016/j.sbspro.2014.10.096

Forrest-bank, S. S., Nicotera, N., Anthony, E. K., \& Jenson, J. M. (2015). Children and Youth Services Review Finding their Way : Perceptions of risk, resilience , and positive youth development among adolescents and young adults from public housing neighborhoods, 55, 147-158.

Gidlow, C. J., Ellis, N. J., \& Bostock, S. (2012). Development of the neighbourhood green space tool (NGST). Landscape and Urban Planning, 106(4), 347-358.

Kasim, R. S. R., Zulkharnain, A., Hashim, Z., Ibrahim, W. N. W., \& Yusof, S. E. (2014). Regenerating youth development through entrepreneurship. Procedia-Social and Behavioral Sciences, 129, 322-327. 
Li, H., Liebenberg, L., \& Ungar, M. (2015). Children and Youth Services Review Understanding service provision and utilization for vulnerable youth : Evidence from multiple informants, 56, 18-25

Marouf, N., Che-Ani, A. I., Tawil, N. M., Johar, S., \& Tahir, M. M. (2015). Development of designing criteria in children's urban play space in Iran-review of literature. Journal of Sustainable Development, 8(2), 113.

Nyambe, A., Van Hal, G., \& Kampen, J. K. (2016). Screening and vaccination as determined by the Social Ecological Model and the Theory of Triadic Influence: a systematic review. BMC public health, 16(1), 1166.

Sanders, J., \& Munford, R. (2014). Youth-centred practice: Positive youth development practices and pathways to better outcomes for vulnerable youth. Children and Youth Services Review, 46, 160-167. doi:10.1016/j.childyouth.2014.08.020

Schmid, K. L., Phelps, E., \& Lerner, R. M. (2011). Constructing positive futures: modeling the relationship between adolescents' hopeful future expectations and intentional self regulation in predicting positive youth development. Journal of adolescence, 34(6), 1127-35. doi:10.1016/j.adolescence.2011.07.009

Sherry, C. (2017). Accommodating children's activities in the shared spaces of high-density and master-planned developments. Designing Cities with Children and Young People: Beyond Playgrounds and Skate Parks, 123.

Twohig P.L. \& Putnam W. (2002) Group interviews in primary care research: advancing the state of the art or ritualized research? Family Practice 19(3), 278-284.

Van Cauwenberg, J., Cerin, E., Timperio, A., Salmon, J., Deforche, B., \& Veitch, J. (2015). Park proximity, quality and recreational physical activity among mid-older aged adults: moderating effects of individual factors and area of residence. International Journal of Behavioral Nutrition and Physical Activity, $12(1), 46$.

Van Loon, J., Frank, L. D., Nettlefold, L., \& Naylor, P.-J. (2014). Youth physical activity and the neighbourhood environment: examining correlates and the role of neighbourhood definition. Social Science \& Medicine (1982), 104, 107-15. doi:10.1016/j.socscimed.2013.12.013

Vilhelmson, B., Thulin, E., \& Elldér, E. (2017). Where does time spent on the Internet come from? Tracing the influence of information and communications technology use on daily activities. Information, Communication \& Society, 20(2), 250-263.

Yeshpanova, D., Narbekova, G., Biyekenova, N., Kuchinskaya, J., \& Mukanova, O. (2014). Social Activity of Youth in Social and Cultural Measurement. Procedia - Social and Behavioral Sciences, 140, 109-114. doi:10.1016/j.sbspro.2014.04.394

Yusup, M., Arshad, A. F., Abdullah, Y. A., \& Ishak, N. S. A. (2016). Coastal Land Reclamation: Implication towards development control system in West Malaysia. Environment-Behaviour Proceedings Journal, 1(1), 354-361.

Zieff, S. G., Chaudhuri, A., \& Musselman, E. (2016). Creating neighborhood recreational space for youth and children in the urban environment: Play (ing in the) Streets in San Francisco. Children and youth services review, 70, 95-101. 